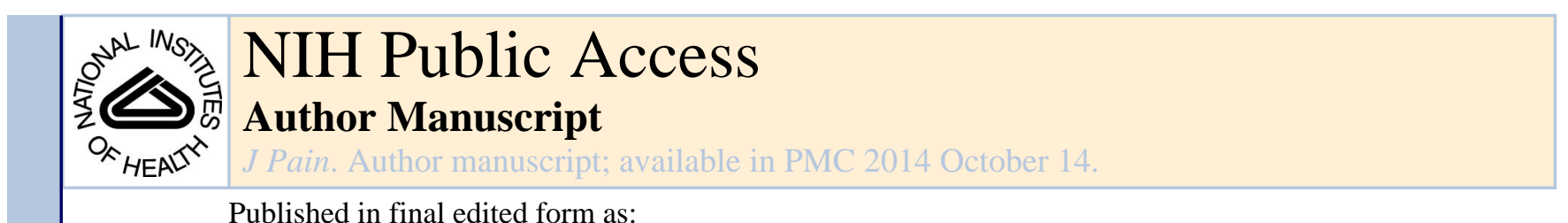

Published in final edited form as:

J Pain. 2014 May ; 15(5): 535-549. doi:10.1016/j.jpain.2014.01.498.

\title{
From Peripheral to Central: The Role of ERK Signaling Pathway in Acupuncture Analgesia
}

\author{
Ji-Yeun Park ${ }^{\star}$, , Jongbae J. Park ${ }^{\ddagger} \S$, Songhee Jeon", Ah-Reum Doo ${ }^{\star}$, Seung-Nam Kim ${ }^{\star}{ }^{\dagger}$, \\ Hyangsook Lee*, Younbyoung Chae ${ }^{*}$, , William Maixner ${ }^{\S}$, Hyejung Lee ${ }^{*} \dagger$, and Hi-Joon \\ Park ${ }^{*}, \mathbb{I}$ \\ "Studies of Translational Acupuncture Research, Acupuncture and Meridian Science Research \\ Center, Kyung Hee University, Seoul, Republic of Korea \\ tDepartment of Korean Medical Science, Graduate School of Korean Medicine, Kyung Hee \\ University, Seoul, Republic of Korea \\ ¥Asian Medicine and Acupuncture Research, Department of Physical Medicine and \\ Rehabilitation, Chapel Hill, North Carolina \\ $\S$ Center for Pain Research and Innovation, UNC School of Dentistry, Chapel Hill, North Carolina \\ "Dongguk University Research Institute of Biotechnology, Seoul, Republic of Korea \\ ICarolina Asia Center, UNC-Chapel Hill, Chapel Hill, North Carolina
}

\begin{abstract}
Despite accumulating evidence of the clinical effectiveness of acupuncture, its mechanism remains largely unclear. We assume that molecular signaling around the acupuncture needled area is essential for initiating the effect of acupuncture. To determine possible bio-candidates involved in the mechanisms of acupuncture and investigate the role of such bio-candidates in the analgesic effects of acupuncture, we conducted 2 stepwise experiments. First, a genome-wide microarray of the isolated skin layer at the GB34-equivalent acupoint of C57BL/6 mice 1 hour after acupuncture found that a total of 236 genes had changed and that extracellular signal-regulated kinase (ERK) activation was the most prominent bio-candidate. Second, in mouse pain models using formalin and complete Freund adjuvant, we found that acupuncture attenuated the nociceptive behavior and the mechanical allodynia; these effects were blocked when ERK cascade was interrupted by the mitogen-activated protein kinase kinase (MEK)/mitogen-activated protein kinase (MAPK) inhibitor U0126 $(.8 \mu \mathrm{g} / \mu \mathrm{L})$. Based on these results, we suggest that ERK phosphorylation
\end{abstract}

C2014 by the American Pain Society

Address reprint requests to Hi-Joon Park, KMD, PhD, Kyung Hee University, Acupuncture and Meridian Science Research Center, 26 Kyungheedae-ro, Dongdaemun-gu, Seoul 130-701, Republic of Korea. acufind@khu.ac.kr.

J.-Y.P., J.J.P. and S.J. contributed equally to this work.

The authors declare that there are no financial or other relationships that might lead to a conflict of interest.

The content is solely the responsibility of the authors and does not necessarily represent the official views of the National Institutes of Health.

Supplementary data accompanying this article are available online at www.jpain.org and www.sciencedirect.com.

Supplementary Data: Supplementary data related to this article can be found at http://dx.doi.org/10.1016/j.jpain.2014.01.498. 
following acupuncture needling is a biochemical hallmark initiating the effect of acupuncture including analgesia.

Perspective-This article presents the novel evidence of the local molecular signaling in acupuncture analgesia by demonstrating that ERK activation in the skin layer contributes to the analgesic effect of acupuncture in a mouse pain model. This work improves our understanding of the scientific basis underlying acupuncture analgesia.

\section{Keywords}

Acupuncture analgesia; extracellular signal-regulated kinase; skin tissues; mouse pain model

Pain significantly interferes with quality of life and functioning. ${ }^{61}$ Diverse pharmacologic treatments ${ }^{3,49}$ and analgesic injections ${ }^{24,31}$ are used to relieve pain. Patients, however, often seek alternatives because of unsatisfactory results or side effects of the conventional approaches. ${ }^{49,53}$

Acupuncture has gained recognition as a modality for pain treatment. ${ }^{51,63}$ Accumulated evidence supports the clinical effectiveness of acupuncture to treat knee osteoarthritis, ${ }^{46}$ headaches, ${ }^{65}$ and low back pain. ${ }^{4,58}$ Despite substantial research endeavors on the analgesic mechanisms of acupuncture, ${ }^{18,29,44}$ various mechanisms related to acupuncture needling and its effects remain largely vague.

It has been recognized that understanding the molecular and cellular mechanisms of nociception is important for the treatment of pain, ${ }^{62}$ which may also provide insight into the therapeutic value of acupuncture and pave the way for the development of mechanism-based therapeutic strategies for pain management. ${ }^{39}$ Some have speculated that the changes involved in the local manipulation of acupuncture needles play a crucial role in triggering the clinical effects of acupuncture, including pain alleviation. ${ }^{28,33,39,64}$ Intriguingly, Goldman and his colleagues recently reported that acupuncture needling induces an increase in adenine nucleotides (adenosine triphosphate [ATP], adenosine diphosphate [ADP], and adenosine monophosphate [AMP]) and adenosine in the muscle and that the adenosine A1 receptor is necessary for the local antinociceptive action of acupuncture to function. ${ }^{19}$ Langevin et al suggested that acupuncture-induced morphologic changes in the subcutaneous loose connective tissue and fibroblasts play crucial roles in cytoskeletal remodeling, ${ }^{36,37}$ whereas the relationship between the connective tissue changes and the therapeutic effects remain unrevealed. Although previous studies have provided important information about the local changes around acupuncture points, ${ }^{1,19,26,56}$ few studies have investigated the local molecular and cellular mechanisms that are responsible for the analgesic effects of acupuncture. Therefore, we hypothesized that molecular signaling around the needled acupuncture point is an essential part of the clinical effect of acupuncture.

To test this hypothesis, the aims of this study were 1) to identify molecular entities following acupuncture needling at the local skin level and 2) to investigate the role of such identified molecules on the analgesic effects of acupuncture. To our knowledge, this is the first study to report molecular changes related to acupuncture needling and to suggest that 
they are biochemical hallmarks that initiate the effects of acupuncture, including analgesic effects.

\section{Methods}

\section{Experimental Animals}

Male C57BL/6 mice of 8 to 10 weeks of age, weighing 20 to $25 \mathrm{~g}$ (Samtaco, Seoul, Korea), were used in all the experiments. They were maintained on a 12-hour/12-hour light/dark schedule with free access to food and water. All the experiments were approved by the Kyung Hee University Animal Care Committee for animal welfare (KHUASP(SE)-11-022) and were performed according to the guidelines of the National Institutes of Health and the Korean Academy of Medical Sciences and followed the recommendations of the International Association for the Study of Pain.

\section{Acupuncture Needling and Stimulation}

Acupuncture was performed at the GB34 (Yangneungcheon) acupuncture point, around the intersection of the lines from the anterior border to the head of the fibula (Fig 1A). ${ }^{60}$ GB34 is known to have an effect on pain and motor dysfunction. ${ }^{47,54}$ In our pilot experiment, this acupoint showed more significant analgesic effect than adjacent points in the formalin test (Supplementary Fig S1). Mice were immobilized in a holder and acupuncture needles (.18 $\mathrm{mm}$ in diameter and $8 \mathrm{~mm}$ in length; Haenglim-seoweon Acuneedle Co, Gyeonggi-Do, Korea) were inserted to a depth of $3 \mathrm{~mm}$ at bilateral acupuncture points. Then the acupuncture needles were turned at a rate of 2 spins per second bidirectionally ( 1 spin consisted of clockwise rotation of $180^{\circ}$ and a counterclockwise rotation of $180^{\circ}$ ) for 10 seconds. The acupuncture needles were removed 10 minutes later. Information regarding the depth of insertion and the rate of rotation for the acupuncture needling technique using Acusensor (acupuncture needling force and motion sensor system; Stromatec, Inc, Burlington, VT) is presented in Figs 1B-1E. ${ }^{14}$ The linear translation of the needle (ie, displacement; Fig 1C) and the turning of the needle (ie, rotation; Fig 1D) on its longitudinal axis were measured using a motion sensor. The rotational force acting on the needle to resist its rotation (ie, torque; Fig 1E) was measured using a force sensor.

\section{Skin Sample Collection}

One day before skin collection, the hair on the legs was removed from the skin using electronic hair clipper (Voguers, Gyeonggi-Do, Korea). After acupuncture needling, the mice were anesthetized with ether, and the bilateral skin layer tissues surrounding the acupuncture needled point $(5 \mathrm{~mm}$ in diameter and $600 \mu \mathrm{m}$ thick, consisting of the epidermis and dermis) were collected immediately and stored at $-80^{\circ} \mathrm{C}$. For the control group, the same part of the tissue from control mice was collected using the same methods. All these skin layers were pulverized in liquid nitrogen and homogenized together.

\section{cDNA Microarray Analysis}

The mice were divided into 2 groups: the control group $(\mathrm{CON})$ and the group that received acupuncture needling at the GB34 acupuncture point (ACU) (each $n=3)$. The mice from the $\mathrm{CON}$ group were also immobilized for the same length of time as the mice receiving 
acupuncture to induce an equal amount of stress as acupuncture treatment. At exactly 60 minutes after acupuncture needling, the skin layer tissues were collected.

Total RNA was extracted from the skin samples using an RNeasy mini kit (Qiagen GmbH, Hilden, Germany). The isolated RNA was quantified using a NanoDrop ND-1000 spectrophotometer (NanoDrop Technologies, Wilmington, DE). A microarray was performed using a GeneChip Mouse Gene 1.0 ST Array (Affymetrix Inc, Santa Clara, CA) following Affymetrix GeneChip preprocessing (Affymetrix Microarray Suite User Guide version 5 edition; Affymetrix Inc). The total RNA isolated from the skin layer was mixed with a T7-(N)6 primer, and Poly A RNA controls were used to synthesize the first-strand complementary DNA (cDNA). The first-cycle, first-strand cDNA and then the secondstrand cDNA were synthesized. Then the first-cycle cRNA and the second-cycle, singlestrand cDNA (ss cDNA) were synthesized and purified. The ss cDNA was fragmented, then labeled, and hybridized to the GeneChip using a Fluidics 450 station and GeneChip Operation Software (Affymetrix Inc).

The gene expression values were normalized by quantile methods across all the samples. Then, to compare the CON and ACU groups, the fold change and Student t-test were applied to select the differentially expressed genes (DEGs) using a fold change threshold of 1.5 -fold and a $P$ value $<.05$ to indicate significance. A volcano plot was used to better visualize and compare the 2 DEG methods. The 1.5-fold DEGs were clustered using the GenPlexTM v3.0 software (ISTECH Inc, Seoul, Korea). The 1.5-fold DEGs were then mapped to relevant pathways using the same software. The pathway resources were provided by the Kyoto Encyclopedia of Genes and Genomes database.

\section{Reverse Transcriptase Polymerase Chain Reaction (RT-PCR) Analysis}

Total RNA from the skin samples of CON and ACU groups (each $n=6$ ) was isolated using TRIzol reagent (Invitrogen, Carlsbad, CA). The cDNAs were synthesized using SuperScript III First-Strand (Invitrogen, Carlsbad, CA) and amplified using EconoTaq PLUS GREEN 2x Master Mix (Lucigen, Middleton, WI), following the manufacturer's instructions and using the following primers: fos forward: 5'-CCGATCGGAGGAGGGAGC-3', fos reverse: 5'GGC CTCCTCAGACTCT GGGG- $3^{\prime}, n r 4 a 1$ forward: $5^{\prime}$ GCTTTCCCCGGCTTGGCACC-3', $n$ r4al reverse: $5^{\prime}$ CACCATGCCCACAGCCAGGC-3', duspl forward: $5^{\prime}-$ CGGGGCACCTCTACTACCAC-3', duspl reverse: 5'-CCAGCTCCCATGAGCCTCTC-3', nfkbia forward: 5'-CGAGCCCTGGAAGCAGCAGC-3', nfkbia reverse: 5'CTACACTGGCCAGGCAGCCC-3', gapdh forward: 5'GGCCGGTGCTGAGTATGTCG-3', and gapdh reverse: 5' $^{\prime}$ GTGTGGTCATGAGCCCTTCC- $3^{\prime}$. Initial denaturation at $94^{\circ} \mathrm{C}$ for 10 minutes was followed by 30 cycles of denaturation at $94^{\circ} \mathrm{C}$ for 1 minute, then annealing for 1 minute at different temperatures $\left(58-63^{\circ} \mathrm{C}\right)$ for each primer, extension at $72^{\circ} \mathrm{C}$ for 2 minutes and, finally, 1 cycle at $72^{\circ} \mathrm{C}$ for 10 minutes.

The PCR products were separated on $2 \%$ agarose gels, stained with SYBR Green (Invitrogen, Eugene, OR), and photographed under ultraviolet light. The results were analyzed using the image analysis program CoreBio i-MAX (CoreBio Co, Seoul, Korea) 
and the intensities of the bands were measured using the ImageMasterTotal-Lab image analysis software (Amersham Biosciences, Piscataway, NJ). The amounts of target PCR products were normalized against glyceraldehyde 3-phosphate dehydrogenase (GAPDH).

\section{Western Blot Analysis}

Skin samples were homogenized in $200 \mu \mathrm{L}$ of lysis buffer, which comprised 1\% NP-40, 20 $\mathrm{mM}$ hydroxyethyl piperazineethanesulfonic acid ( $\mathrm{pH} 7.5$ ), $150 \mathrm{mM} \mathrm{NaCl}, 10 \%$ glycerol, 1 $\mathrm{mM}$ phenylmethanesulfonyl fluoride, $.7 \mu \mathrm{g} / \mathrm{mL}$ Pepstatin, $60 \mathrm{mM}$ B-Glucoside, phosphatase inhibitor cocktail tablets, and protease inhibitor cocktail tablets in distilled water. After homogenization, the samples were centrifuged at $12,000 \mathrm{rpm}$ for 15 minutes at $4{ }^{\circ} \mathrm{C}$ and the supernatants were collected. The amount of protein was measured using the Bradford assay. For Western blot analysis, equal protein concentrations (30 $\mathrm{mg}$ of total protein) were separated by a $10 \%$ sodium dodecyl sulfate-polyacrylamide gel electrophoresis and then transferred to a polyvinylidene fluoride membrane (Amersham Biosciences, Buckinghamshire, United Kingdom). The membrane was blocked in 5\% skim milk in Trisbuffered saline containing .1\% Tween-20 (TBS-T) and incubated with the primary antibodies overnight at $4^{\circ} \mathrm{C}$. The primary antibodies were rabbit phosphorylated extracellular signal-regulated kinase (phospho-ERK), ERK, phospho-p38, p38, phosphorylated c-Jun N-terminal kinase (phospho-JNK), JNK, nuclear factor kappa B

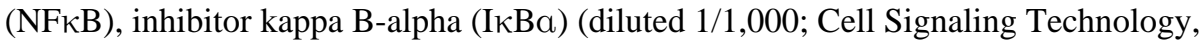
Beverly, MA), and $\beta$-actin (diluted 1/1,000; Sigma-Aldrich, St. Louis, MO). Then, the membrane was incubated with the secondary horseradish peroxidase-conjugated goat antirabbit antibody (diluted 1/1,000; Pierce, Rockford, IL). The membrane was visualized using a chemiluminescence kit (Super Signal West Pico; Pierce). The signal intensities from the immunoblots were analyzed by densitometry.

\section{Histologic Analysis}

The skin samples were immediately put into $4 \%$ formalin solution for fixation. A few days later, the samples were embedded in paraffin and cut into $4-\mu \mathrm{m}$ slices. The sections were placed on microscope slides. To remove the paraffin, the sections were incubated in xylene and then hydrated in 100\% ethanol and 95\% ethanol. The sections were washed in distilled $\mathrm{H}_{2} \mathrm{O}$.

As part of an immunohistochemistry analysis, the sections were incubated in 3\% hydrogen peroxide for 10 minutes, washed in wash buffer (TBS-T), and incubated in blocking solution (TBS-T with 5\% normal goat serum) for 1 hour. The blocking solution was removed and the primary rabbit phospho-ERK antibody (diluted 1/200; Cell Signaling Technology) was diluted in blocking solution and added to each section. These solutions were incubated overnight at $4{ }^{\circ} \mathrm{C}$. Then, the antibody solution was removed, and the sections were rinsed with wash buffer. The sections were incubated with biotinylated anti-rabbit immunoglobulin $\mathrm{G}(\mathrm{IgG})$ (diluted 1/1,000; Vector Laboratories Inc, Burlingame, CA) for 1 hour. Then, they were incubated with $\mathrm{ABC}$ reagent (Vector Laboratories Inc) and incubated in .02\% diaminobenzidine and $.003 \%$ hydrogen peroxide in $1 \mathrm{M}$ Tris-buffered saline $(\mathrm{pH} 7.5)$. As soon as the sections were developed, the slides were immersed in distilled $\mathrm{H}_{2} \mathrm{O}$. The sections were counterstained with hematoxylin, dehydrated in $95 \%$ and $100 \%$ ethanol, 
incubated in xylene, and mounted. Pictures of the skin layers were taken using a bright-field microscope (BX51; Olympus, Tokyo, Japan).

For immunofluorescence analysis, the sections were washed in wash buffer and then incubated in blocking solution for 1 hour. The blocking solution was removed, and the primary antibodies—rabbit phospho-ERK (diluted 1/200; Cell Signaling Technology), mouse fibroblast (5B5) (diluted 1/50; Abcam, Cambridge, United Kingdom), and mouse cytokeratin 7 (CK7) (diluted 1/100; Abcam)—were diluted in blocking solution and added to the sections. These solutions were incubated overnight at $4{ }^{\circ} \mathrm{C}$. The antibody solution was removed and the sections were washed with wash buffer. The sections were incubated with Alexa Fluor 488 anti-mouse IgG (diluted 1:5,000; Invitrogen, Carlsbad, CA) and Alexa Fluor 594 anti-rabbit IgG (diluted 1:5,000; Invitrogen, Carlsbad, CA) for 1 hour in a dark room and mounted using mounting medium with 4',6-diamidino-2-phenylindole (DAPI) (Vector Laboratories Inc). The phospho-ERK, 5B5, and CK7-positive signals were detected using confocal microscopy (FV10i; Olympus).

\section{The Formalin-Induced Mouse Pain Model and Behavior Assessment}

Formalin-Induced Mouse Pain Model-The formalin test that was used to assess analgesics has 2 phases of nociceptive response. Phase 1 is produced by direct nerve stimulation and phase 2 involves inflammation-induced pain. ${ }^{52}$

The mice were divided into 5 treatment groups: treatment with formalin only (FOR), treatment with formalin and U0126 administration (FOR $+\mathrm{U})$, treatment with formalin and acupuncture needling at the GB34 acupuncture point (ACU), treatment with formalin with acupuncture needling at the GB34 acupuncture point and U0126 administration (ACU + U), and the control procedure $(\mathrm{CON})(\mathrm{n}=8$ in each group). The mice in the FOR, FOR $+\mathrm{U}$, $\mathrm{ACU}$, and $\mathrm{ACU}+\mathrm{U}$ groups were injected with $1 \%$ formalin $(20 \mu \mathrm{L}$, diluted in saline) subcutaneously into the plantar surface of the right hind paw as previously described. ${ }^{29}$ Mice in the FOR + U and ACU + U groups were also injected with $10 \mu \mathrm{L}$ of $.8 \mu \mathrm{g} / \mu \mathrm{L}$ U0126 at GB34 15 minutes before acupuncture needling. Mice in the ACU and ACU + U groups were treated with acupuncture right after formalin injection for 10 minutes while immobilized. Mice in the CON, FOR, and FOR + U groups were also immobilized for 10 minutes to induce an equal amount of stress. An equal volume of saline $(20 \mu \mathrm{L})$ was injected into the right hind paw of the mice in the CON group as a control for the formalin injection. Mice in the CON, FOR, and ACU groups were injected with an equal volume of dimethylsulfoxide (DMSO) $(10 \mu \mathrm{L})$ at GB34 15 minutes before the acupuncture needling as a control for U0126.

Nociceptive Behavior Assessment-To assess nociceptive behavior, all the mice were acclimatized in a clear acrylic chamber that measured $20 \mathrm{~cm}$ in diameter and height for 30 minutes before the experiment. After acupuncture needling, the mice were immediately placed back in the same chamber, and the nociceptive responses of the mice were recorded using a video camera for 20 minutes (from 10 to 30 minutes after the formalin injection). The total time (seconds) spent licking, biting, and flinching the formalin-injected hind paw was measured and analyzed during each 5-minute block. 
Mechanical Threshold Assessment-To assess mechanical allodynia, different groups of mice were habituated in a clear acrylic box $(8 \times 10 \times 10 \mathrm{~cm}$, with a gridded floor $)$ for 2 days before the start of the experiments. Prior to each experiment, all the mice were habituated for 1 hour. After formalin injection and acupuncture needing, the mice were immediately placed back in the same clear box, and the mechanical allodynia of the bilateral hind paws was assessed using electronic Von Frey filaments (IITC, Woodland Hills, CA). Each Von Frey filament, exerting .6 g of force, was applied a total of 10 times to the plantar surface of each hind paw for 1 second at 5-second intervals. The frequency of the positive responses from a total of 10 trials was calculated for each foot.

\section{The Complete Freund Adjuvant (CFA)-Induced Mouse Pain Model and Behavior Assessment}

CFA-Induced Mouse Pain Model-The mice were divided into 5 treatment groups: treatment with CFA only (CFA), treatment with CFA and U0126 administration (CFA + U), treatment with CFA and acupuncture needling at the GB34 acupuncture point (ACU), treatment with CFA with acupuncture needling at the GB34 acupuncture point and U0126 administration $(\mathrm{ACU}+\mathrm{U})$, and control $(\mathrm{CON})(\mathrm{n}=8$ in each group). The mice in the CFA, $\mathrm{CFA}+\mathrm{U}, \mathrm{ACU}$, and $\mathrm{ACU}+\mathrm{U}$ groups were injected subcutaneously into the plantar surface of the right hind paw as previously described ${ }^{29}$ with $100 \mu \mathrm{L}$ of CFA emulsion solution (suspended in oil, mixed with an equal volume of saline) at day 0 . Mice in the CFA $+\mathrm{U}$ and $\mathrm{ACU}+\mathrm{U}$ groups were injected with $10 \mu \mathrm{L}$ of $.8 \mu \mathrm{g} / \mu \mathrm{L}$ U0126 at GB34 15 minutes before acupuncture needling. On day 4, the mice in the ACU and ACU + U groups were treated with acupuncture for 10 minutes while they were immobilized. The mice in the CON, CFA, and CFA + U groups were also immobilized for 10 minutes to induce an equal amount of stress as in the acupuncture groups. An equal volume of saline $(100 \mu \mathrm{L})$ was injected in the right hind paw of the CON group mice as a control for the CFA injection. The mice in the $\mathrm{CON}, \mathrm{CFA}$, and ACU groups were injected with an equal volume of DMSO $(10 \mu \mathrm{L})$ at the GB34 15 minutes before acupuncture needling as a control for U0126.

Mechanical Threshold Assessment-To assess mechanical allodynia, all the mice were habituated in a clear acrylic box $(8 \times 10 \times 10 \mathrm{~cm}$, with a gridded floor $)$ for 2 days before the mechanical threshold assessment. Prior to each experiment, all the mice were habituated for 1 hour. After acupuncture needing on day 4, the mice were immediately placed back in the same clear box, and the mechanical allodynia of the bilateral hind paws was assessed using electronic Von Frey filaments. Each Von Frey filament, exerting .6 g of force, was applied a total of 10 times to the plantar surface of each hind paw for 1 second at 5 -second intervals. The frequency of the positive responses from a total of 10 trials was calculated for each foot.

\section{Drug Administration}

To inhibit ERK activation on the skin layer, the mitogen-activated protein kinase kinase (MEK)/mitogen-activated protein kinase (MAPK) inhibitor U0126 (Promega, Madison, WI) was used. U0126 acts as a direct inhibitor of MEK activity ${ }^{15}$ and has been used as a specific inhibitor of the p42/44 MAPK pathway. ${ }^{13,43}$ The mice were slightly anesthetized, and $10 \mu \mathrm{L}$ of U0126 was dissolved in DMSO (.4 and $.8 \mu \mathrm{g} / \mu \mathrm{L})$ and injected into the GB34 acupuncture 
point intradermally using a .5-mL syringe (BD Biosciences, San Jose, CA) 15 minutes before acupuncture needling, as previously described. ${ }^{12}$ The control mice were injected an equal volume of DMSO.

\section{Statistical Analysis}

GraphPad Prism 5 software (GraphPad Software Inc, San Diego, CA) was used for the statistical analysis. All the data were expressed as the mean \pm standard error of the mean (SEM). The statistical analysis was performed using Student t-test, 1-way analysis of variance (ANOVA) with the Newman-Keuls post hoc test, and 2-way ANOVA followed by a Bonferroni post hoc test. In all of the analyses, the differences were considered statistically significant at $P<.05$.

\section{Results}

\section{Identifying Molecular Biomarkers Induced by Acupuncture Needling in the Skin Layers Using a cDNA Microarray}

To identify biomarkers that changed after the acupuncture needling, a cDNA microarray and correlation matrix plot analysis was performed between the acupuncture-treated (ACU) and control (CON) groups. The location of the acupuncture point and needling details are shown in Fig 1. After acupuncture needling, a total of 236 genes changed, compared with the CON group (fold change threshold of 1.5 -fold and $P<.05$ ). Of those genes, 110 genes were upregulated and 126 genes were down-regulated (Fig 2). The 1.5-fold DEGs were mapped to different molecular pathways. Using the up-regulated genes, a total of 29 pathways were mapped; among them, 7 pathways changed significantly: the MAPK signaling pathway, the B-cell receptor signaling pathway, the T-cell receptor signaling pathway, the Toll-like receptor signaling pathway, the circadian rhythm, the C21-steroid hormone metabolism, and the p53 signaling pathway (Table 1). Using the down-regulated genes, a total of 6 pathways were mapped, but none of the pathways showed significant changes.

The gene expression changes, including those in the up-regulated pathways, were confirmed with RT-PCR. Sixty minutes after acupuncture needling, the mRNA levels of fos $(P<.001)$, $n r 4 a l(P<.01)$, duspl $(P<.001)$, and nfkbia $(P<.01)$ had increased significantly, compared with the control (Fig 3).

\section{Acupuncture-Induced Changes in the Proteins of the MAPK Pathway: Remarkable Increase of Phospho-ERK After Acupuncture Needling}

To find a specific biomarker, we focused on the MAPK pathway, as suggested by the results of the previous experiment, and we analyzed the activity of the MAPK family, ERK, p38, and JNK after acupuncture needling. Five minutes after acupuncture needling, the activation of phospho-ERK was significantly higher than in the CON group $(P<.05)$ and then it gradually decreased for 30 minutes (Fig 4A). Five minutes after acupuncture needling, the phosphorylation of $\mathrm{p} 38$ was also elevated compared with the $\operatorname{CON} \operatorname{group}(P<.05)$,but the elevation was not as high as that of phospho-ERK (Fig 4B). The changes in the phosphorylation of JNK were not significant (Fig 4C). These changes were observed in the normal mice and in the mice with pain (Supplementary Fig S2). 
To investigate the location of ERK activation in the skin layer, a histologic analysis with immunohistochemistry and immunofluorescence was performed. Five minutes after acupuncture needling, the activation of ERK was detected in the epidermis and the dermis, and these signals were diminished after U0126 (MEK/MAPK inhibitor) administration (Fig 5). To investigate the type of cell undergoing ERK activation, the tissue was costained for phospho-ERK, a fibroblast marker, and a keratinocyte marker, and then visualized by immunofluorescence (Fig 6). Five minutes after acupuncture needling, activation of ERK was detected in the keratinocytes of the epidermis (colocalized with CK7) and in the fibroblast of the dermis (colocalized with 5B5), suggesting that acupuncture phosphorylates ERK in both the keratinocytes and fibroblast at the acupuncture point.

\section{The Involvement of Local Molecular Changes in the Analgesic Effects of Acupuncture}

\section{The Impact of Acupuncture on the Formalin-Induced Pain Model and} Inhibition of the Acupuncture Effect by U0126-To examine whether acupunctureinduced ERK activation is involved in the analgesic effects of acupuncture, we used the MEK/MAPK inhibitor U0126 in the formalin-induced and CFA-induced mouse pain model. To verify that the intradermal injection of U0126 worked successfully in the skin layer, the level of ERK phosphorylation was determined by Western blotting. Five minutes after acupuncture needling, phospho-ERK activation was elevated and U0126 (.4 and $.8 \mu \mathrm{g} / \mu \mathrm{L})$ inhibited the acupuncture-induced ERK activation in a dose-dependent manner (Supplementary Fig S3A). Then we investigated whether the intradermal injection of U0126 worked only at the local sites. Acupuncture was performed bilaterally, but U0126 was injected only on the left leg. As a result, U0126 inhibited acupuncture-induced ERK activation only on the left leg and did not affect the other side (Supplementary Fig S3B), indicating that U0126 successfully inhibited ERK activation locally.

Finally, we investigated whether local ERK activation caused by acupuncture needling was linked to analgesia using the formalin-induced and CFA-induced pain models. To analyze formalin-induced nociceptive behavior, the summation of time spent licking, biting, and flinching the formalin-injected hind paw during the second phase (10-30 minutes after formalin injection) was examined (Fig 7A). The nociceptive behaviors of the FOR group were significantly higher than those of the $\mathrm{CON}$ group $(P<.001)$. The FOR $+\mathrm{U}$ group showed the same degree of nociceptive behaviors as the FOR group. Thus, the administration of U0126 into the skin layer did not affect the nociceptive behavior. Acupuncture needling diminished formalin-induced nociceptive behavior significantly, compared with the FOR group $(P<.001)$. The acupuncture effect in the formalin-induced pain model was significantly suppressed by U0126 injection into the skin layer $(P<.01)$.

The summation of time spent licking, biting, and flinching the formalin-injected hind paw during the second phase (10-30 minutes after formalin injection), within each 5-minute block, was also analyzed (Fig 7B). Starting from the period of 15 to 20 minutes, the nociceptive behavior of all of the formalin-treated groups was significantly higher than that of the CON groups ( $P<.001$ during 15-20, 20-25, and 25-30 minutes). The ACU group showed decreased pain behavior, compared with the formalin group, and this difference was the most significant during 25 to 30 minutes $(P<.05$ during 15-20 and 20-25 minutes, $P<$. 
01 during 25-30 minutes). U0126 blocked the acupuncture effect in this pain model significantly during 25 to 30 minutes $(P<.01)$.

Next, the formalin-induced mechanical allodynia on the right hind paw during the second phase was analyzed (Fig 7C). The formalin injection significantly increased mechanical allodynia compared with the saline injection $(P<.001)$. The U0126 injection alone did not affect formalin-induced pain behavior in the FOR $+\mathrm{U}$ group. Acupuncture needling reduced the formalin-induced mechanical allodynia significantly, compared with the FOR group $(P$ $<.001)$, and this effect was reversed by the U0126 injection into the skin layer $(P<.001)$. To gather more detailed information, mechanical allodynia during the second phase (10-30 minutes after the formalin injection) was analyzed within each 5-minute block (Fig 7D). As early as 15 minutes after the formalin injection, nociceptive behavior in all of the formalin groups was significantly higher than in the CON groups $(P<.05$ at 15 minutes, $P<.01$ at 20 minutes, $P<.001$ at 25 and 30 minutes). The ACU group showed a significant decrease of mechanical allodynia, compared with formalin, as early as 20 minutes after formalin injection ( $P<.01$ at 20 minutes, $P<.001$ at 25 and 30 minutes). The effect of acupuncture on the formalin-induced mechanical allodynia was blocked by the U0126 injection into the skin layer $(P<.05$ at 15 minutes, $P<.001$ at 20 and 25 minutes, $P<.01$ at 30 minutes $)$. The mechanical allodynia on the contralateral side of the hind paw did not exhibit any differences among all of the groups (Supplementary Fig S4).

\section{Effect of Acupuncture on CFA-Induced Mechanical Threshold and Inhibition of the Acupuncture Effect by U0126-We confirmed the analgesic effect of} acupuncture and the blocking effect of U0126 on CFA-induced mechanical allodynia (Fig 8A). Before the CFA injection, the mechanical threshold of the baseline was equivalent in all groups. Four days after the CFA injection in the hind paw, mechanical allodynia was significantly higher than in the CON group $(P<.001)$. The mechanical allodynia of the CFA $+\mathrm{U}$ group was the same as in the CFA group. Acupuncture needling significantly attenuated the CFA-induced mechanical allodynia, compared with the CFA group, from 10 to 30 minutes $(P<.001)$. The analgesic effect of acupuncture in the CFA-induced mechanical allodynia was attenuated by the U0126 injection into the skin layer $(P<.05$ at 10 minutes, $P$ $<.001$ at 20 and 30 minutes). As a control, the mechanical allodynia on the left side of the hind paw did not show differences among all groups (Fig 8B).

\section{Discussion}

Although it has been suggested that the suitable responses induced by the manipulation of needles play an important role in initiating the clinical effects of acupuncture, ${ }^{28,39}$ the biomedical consequence of such manipulation has not been determined. In this study, we found that acupuncture needling provoked ERK activation in the fibroblasts and keratinocytes of the skin layer and that the analgesic effect of acupuncture was blocked by the MEK/MAPK inhibitor U0126. These results suggest that ERK activation in the skin layer is a key inducer of the analgesic effect of acupuncture. To our knowledge, this is the first study to explore the molecular changes around the acupuncture point in relation to the analgesic effects of acupuncture. 
MAPK cascades have been implicated in a broad range of cellular responses to stimuli that result in cell proliferation, differentiation, and apoptosis. ${ }^{17}$ Externally applied mechanical stress or stretch can activate the MAPK signaling pathway, including ERK, p38, and JNK in the fibroblasts or keratinocytes. In addition, p38 and JNK activation is closely related to cell apoptosis and inflammation. ${ }^{10,17,32,41,59}$ In this study, we found that ERK was remarkably more activated than p38 and JNK after acupuncture needling, allowing us to speculate that acupuncture needling may be different from simple mechanical stress or inflammation. ${ }^{25,27}$ Thus, we suggest that increased ERK phosphorylation after acupuncture needling could be a key inducer of the expression of other genes that attenuate pain transmission. Comparison with other intervention methods such as mechanical noxious pinching, touch, or heating might be necessary to confirm whether the changes observed here are specific to acupuncture. Use of a single acupuncture manipulation without other control stimulations could be a limitation of our study and needs to be explored in further studies.

Several gene changes occur and various proteins and secretions are released around the acupuncture point after acupuncture needling. ${ }^{1,26}$ These factors might influence the extracellular environment surrounding the skin tissue and then trigger subsequent processes to produce analgesic effects. Recently, Goldman et $\mathrm{a}^{19}$ reported that ATP and adenosine are released after acupuncture needling around the local muscle or subcutis of the acupuncture point and determined that the analgesic effect of acupuncture requires the adenosine A1 receptor. Zylka et $\mathrm{al}^{23}$ also confirmed the analgesic effect of acupuncture by injecting phosphatidic acid phosphatase, which is known to induce a local adenosine release. ATP, which exists in the cytoplasm of muscle, fibroblasts, and keratinocytes, is immediately released with external stimuli, is degraded into ADP or adenosine, and then induces various intra- and extracellular signal transductions. Although in the present study we did not examine the ATP contents in the ERK inhibitor- treated tissue after acupuncture needling, the ERK activation reached maximum levels in 5 minutes, which preceded the maximum ATP release that occurred 30 minutes after acupuncture needling. ${ }^{19}$ This result suggests that acupuncture-induced ERK activation may precede ATP release in the tissue. Various studies have investigated the relationship between ERK activation and ATP increase, some reporting that ATP increase induces ERK activation ${ }^{2,27,50}$ and others suggesting that nerve growth factor-induced ERK activation provokes ATP increase. ${ }^{16}$ Thus, further research is needed to elucidate these relationships.

Langevin et al suggested that morphologic changes in subcutaneous loose connective tissue, induced by acupuncture needling, play a crucial role in cytoskeletal remodeling, which may stimulate significant downstream cascades. In addition, they reported that the Rho/Rac kinase pathway is involved in the cytoskeletal remodeling process of fibroblasts. ${ }^{36,38}$ Rho/Rac kinase plays a role in cell proliferation, gene expression, and multiple other common cellular functions. ${ }^{5,7}$ Each Rho protein has numerous downstream effectors, and ERK has been reported to be one of the downstream factors of the Rho/Rac pathway. ${ }^{35,67}$ However, the correlation between the effects of acupuncture and this kinase pathway is not clear, and thus the role of the Rho/Rac kinase pathway in the effects of acupuncture must be further explored. 
In addition to the factors mentioned above, our cDNA microarray data suggested that other bio-candidates might be related to acupuncture needling. Several genes, such as fos, $n r 4 a l$, duspl, and nfkbia, which increased after acupuncture needling and are part of the immediate early genes, ${ }^{6}$ respond to various external stimulations and trigger the expression of stress response genes. Among them, nfkbia is categorized in the B and T cell receptor pathways and is involved in local immunomodulation. In some previous studies, $\mathrm{NF \kappa B}$ activation, induced by external stimuli, was reduced by the MEK/MAPK inhibitor U0126. ${ }^{34}$ Moreover, $\mathrm{NF \kappa B}$ activity is modulated by Rho/Rac signaling. ${ }^{45,48}$ In this study, the MEK/MAPK inhibitor decreased the expression levels of $\mathrm{NF} \kappa \mathrm{B}$ and $\mathrm{I} \kappa \mathrm{B} a$ to that seen with acupuncture needling only (Supplementary Fig S5). These results indicate ERK activation might be related to the $\mathrm{NF \kappa B} / \mathrm{I} \kappa \mathrm{B}$ signaling. Further research is needed to determine how these physiological changes affect the therapeutic effect of acupuncture.

From the anatomic point of view, the targeting structure of needle stimulation varies according to the location of each acupuncture point; it is plausible that acupuncture points are on the muscle (eg, ST36, ST32, BL56), artery (eg, LU9, ST9, LR3), or interstitial tissues (eg, HT7, PC7, BL60). ${ }^{11,60}$ Under acupuncture point GB34 are mostly interstitial tissues between 2 bones, the fibula and tibia. Hence, in this study, we focused on the molecular changes from the skin layer around GB34. Thus, we admit the need to further investigate how different anatomic structures under an acupuncture point cause the acupuncture effects.

Although we showed a potential peripheral mechanism of acupuncture-induced analgesia, it is still limited to explaining how these changes of gene expressions in the skin relate to the attenuation of a nociceptive response. Several lines of research proposed that acupuncture can produce analgesic effects by both central and peripheral mechanisms. Considering previous studies, it is possible that the local ERK activation by acupuncture manipulation can act via multiple mechanisms. Activated ERKs generated by acupuncture can enter the nucleus and up-regulate the expression of gene transcription factors or activate nuclear binding proteins, such as NFkB, which may promote the transcription of many genes. The ERK activation therefore induces synthesis and local release of ectonucleotides, such as ATP ${ }^{19}$ and vasoactive substances. ${ }^{26,57}$ Release of these substances influences the extracellular environments surrounding skin tissue cells and may participate in local analgesic effects in part. In addition, these substances also contribute to decreasing pain by activating the sensory afferents of ascending nerve tracks. Acupuncture also has been reported to activate some brain structures such as the periaqueductal gray, nucleus raphe magnus, locus coeruleus, and arcuate nucleus that contribute to descending inhibitory modulation, as well as deactivate multiple limbic areas modulating pain emotion, such as insula and the anterior cingulate cortex. $8,9,20-22,30,42,55,68$

In contrast to previous studies that could not single out target molecules directly associated with the therapeutic effects of acupuncture, $1,39,40$ in the present study, we identified acupuncture-induced biomarkers and demonstrated that ERK activation, especially in the skin tissue, acts as a key inducer to mediate analgesia. However, it is still unclear how these molecular activities are linked to the mechanism of acupuncture analgesia via the opioidergic system, the central nervous system, or the descending inhibitory pathway. ${ }^{44,66}$ 


\section{Supplementary Material}

Refer to Web version on PubMed Central for supplementary material.

\section{Acknowledgments}

The authors thank Dr. Insun Lee for her help with operating Acusensor, and Dr. Samantha Seagall and Selena Beckman-Harned for their assistance in preparing the manuscript.

This research was supported by Basic Science Research Program through the National Research Foundation of Korea funded by the Ministry of Education, Science and Technology (No. 2005-0049404), and a grant of the Korean Health Technology R\&D Project, Ministry of Health and Welfare, Republic of Korea (No. HI13C0540). J.J.P. was supported by the National Institute of Dental and Craniofacial Research of the National Institutes of Health under Award Number K12DE022793.

\section{References}

1. Abraham TS, Chen ML, Ma SX. TRPV1 expression in acupuncture points: Response to electroacupuncture stimulation. J Chem Neuroanat. 2011; 41:129-136. [PubMed: 21256210]

2. Ahmad S, Ahmad A, McConville G, Schneider BK, Allen CB, Manzer R, Mason RJ, White CW. Lung epithelial cells release ATP during ozone exposure: Signaling for cell survival. Free Radic Biol Med. 2005; 39:213-226. [PubMed: 15964513]

3. Angst MS, Phillips NG, Drover DR, Tingle M, Ray A, Swan GE, Lazzeroni LC, Clark JD. Pain sensitivity and opioid analgesia: A pharmacogenomic twin study. Pain. 2012; 153:1397-1409. [PubMed: 22444188]

4. Berman BM, Langevin HM, Witt CM, Dubner R. Acupuncture for chronic low back pain. N Engl J Med. 2010; 363:454-461. [PubMed: 20818865]

5. Boureux A, Vignal E, Faure S, Fort P. Evolution of the Rho family of ras-like GTPases in eukaryotes. Mol Biol Evol. 2007; 24:203-216. [PubMed: 17035353]

6. Burgess ST, McNeilly TN, Watkins CA, Nisbet AJ, Huntley JF. Host transcription factors in the immediate pro-inflammatory response to the parasitic mite Psoroptes ovis. PLoS One. 2011; 6:e24402. [PubMed: 21915322]

7. Bustelo XR, Sauzeau V, Berenjeno IM. GTP-binding proteins of the Rho/Rac family: Regulation, effectors and functions in vivo. Bioessays. 2007; 29:356-370. [PubMed: 17373658]

8. Cabioglu MT, Cetin BE. Acupuncture and immunomodulation. Am J Chin Med. 2008; 36:25-36. [PubMed: 18306447]

9. Chen CY, Chern RS, Liao MH, Chang YH, Hsu JY, Chien CH. The possible neuronal mechanism of acupuncture: Morphologicalevidence of the neuronal connection between groin A-Shi point and uterus. Evid Based Complement Alternat Med. 2013; 2013:429186. [PubMed: 23533481]

10. Chiquet M, Renedo AS, Huber F, Fluck M. How do fibroblasts translate mechanical signals into changes in extracellular matrix production? Matrix Biol. 2003; 22:73-80. [PubMed: 12714044]

11. A Guidebook for College Students. Wonju, Republic of Korea: Eui Bang Publishing Co; 2009. Meridians \& Acupoints Compilation Committee of Korean Oriental Medical Colleges: Principles of Meridians \& Acupoints.

12. Dai Y, Iwata K, Fukuoka T, Kondo E, Tokunaga A, Yamanaka H, Tachibana T, Liu Y, Noguchi K. Phosphorylation of extracellular signal-regulated kinase in primary afferent neurons by noxious stimuli and its involvement in peripheral sensitization. J Neurosci. 2002; 22:7737-7745. [PubMed: 12196597]

13. Davies SP, Reddy H, Caivano M, Cohen P. Specificity and mechanism of action of some commonly used protein kinase inhibitors. Biochem J. 2000; 351:95-105. [PubMed: 10998351]

14. Davis RT, Churchill DL, Badger GJ, Dunn J, Langevin HM. A new method for quantifying the needling component of acupuncture treatments. Acupunct Med. 2012; 30:113-119. [PubMed: 22427464]

15. Favata MF, Horiuchi KY, Manos EJ, Daulerio AJ, Stradley DA, Feeser WS, Van Dyk DE, Pitts WJ, Earl RA, Hobbs F, Copeland RA, Magolda RL, Scherle PA, Trzaskos JM. Identification of a 
novel inhibitor of mitogen-activated protein kinase kinase. J Biol Chem. 1998; 273:18623-18632. [PubMed: 9660836]

16. Ferenz KB, Gast RE, Rose K, Finger IE, Hasche A, Krieglstein J. Nerve growth factor and brainderived neurotrophic factor but not granulocyte colony-stimulating factor, nimodipine and dizocilpine, require ATP for neuroprotective activity after oxygen-glucose deprivation of primary neurons. Brain Res. 2012; 1448:20-26. [PubMed: 22386494]

17. Garrington TP, Johnson GL. Organization and regulation of mitogen-activated protein kinase signaling pathways. Curr Opin Cell Biol. 1999; 11:211-218. [PubMed: 10209154]

18. Gim GT, Lee JH, Park E, Sung YH, Kim CJ, Hwang WW, Chu JP, Min BI. Electroacupuncture attenuates mechanical and warm allodynia through suppression of spinal glial activation in a rat model of neuropathic pain. Brain Res Bull. 2011; 86:403-411. [PubMed: 21958939]

19. Goldman N, Chen M, Fujita T, Xu Q, Peng W, Liu W, Jensen TK, Pei Y, Wang F, Han X, Chen JF, Schnermann J, Takano T, Bekar L, Tieu K, Nedergaard M. Adenosine A1 receptors mediate local anti-nociceptive effects of acupuncture. Nat Neurosci. 2010; 13:883-888. [PubMed: 20512135]

20. Guo ZL, Longhurst JC. Activation of reciprocal pathways between arcuate nucleus and ventrolateral periaqueductal gray during electroacupuncture: involvement of VGLUT3. Brain Res. 2010; 1360:77-88. [PubMed: 20836994]

21. Hahm ET, Lee JJ, Lee WK, Bae HS, Min BI, Cho YW. Electroacupuncture enhancement of natural killer cell activity suppressed by anterior hypothalamic lesions in rats. Neuroimmunomodulation. 2004; 11:268-272. [PubMed: 15249734]

22. Hirano T, Zeredo JL, Kimoto M, Moritaka K, Nasution FH, Toda K. Disinhibitory involvement of the anterior cingulate cortex in the descending antinociceptive effect induced by electroacupuncture stimulation in rats. Am J Chin Med. 2008; 36:569-577. [PubMed: 18543389]

23. Hurt JK, Zylka MJ. PAPupuncture has localized and long-lasting antinociceptive effects in mouse models of acute and chronic pain. Mol Pain. 2012; 8:28. [PubMed: 22524543]

24. Ilfeld BM. Continuous peripheral nerve blocks: A review of the published evidence. Anesth Analg. 2011; 113:904-925. [PubMed: 21821511]

25. Johnson GL, Lapadat R. Mitogen-activated protein kinase pathways mediated by ERK, JNK, and p38 protein kinases. Science. 2002; 298:1911-1912. [PubMed: 12471242]

26. Jou NT, Ma SX. Responses of nitric oxide-cGMP release in acupuncture point to electroacupuncture in human skin in vivo using dermal microdialysis. Microcirculation. 2009; 16:434-443. [PubMed: 19468961]

27. Katz S, Boland R, Santillan G. Modulation of ERK 1/2 and p38 MAPK signaling pathways by ATP in osteoblasts: Involvement of mechanical stress-activated calcium influx, PKC and Src activation. Int J Biochem Cell Biol. 2006; 38:2082-2091. [PubMed: 16893669]

28. Kim, DH. Huangdi's Internal Classic. Seoul: Eui Sung Dang; 2002.

29. Kim HY, Wang J, Lee I, Kim HK, Chung K, Chung JM. Electroacupuncture suppresses capsaicininduced secondary hyperalgesia through an endogenous spinal opioid mechanism. Pain. 2009; 145:332-340. [PubMed: 19646817]

30. Kim W, Kim SK, Min BI. Mechanisms of electroacupuncture-induced analgesia on neuropathic pain in animal model. Evid Based Complement Alternat Med. 2013; 2013:436913. [PubMed: 23983779]

31. Kinjo S, Lim E, Sands LP, Bozic KJ, Leung JM. Does using a femoral nerve block for total knee replacement decrease postoperative delirium? BMC Anesthesiol. 2012; 12:4. [PubMed: 22405052]

32. Kippenberger S, Bernd A, Loitsch S, Guschel M, Muller J, Bereiter-Hahn J, Kaufmann R. Signaling of mechanical stretch in human keratinocytes via MAP kinases. J Invest Dermatol. 2000; 114:408-412. [PubMed: 10692097]

33. Kong J, Fufa DT, Gerber AJ, Rosman IS, Vangel MG, Gracely RH, Gollub RL. Psychophysical outcomes from a randomized pilot study of manual, electro, and sham acupuncture treatment on experimentally induced thermal pain. J Pain. 2005; 6:55-64. [PubMed: 15629419]

34. Kook SH, Jang YS, Lee JC. Involvement of JNK-AP-1 and ERK-NF-kappaB signaling in tensionstimulated expression of type I collagen and MMP-1 in human periodontal ligament fibroblasts. J Appl Physiol. 2011; 111:1575-1583. [PubMed: 21757573] 
35. Laboureau J, Dubertret L, Lebreton-De Coster C, Coulomb B. ERK activation by mechanical strain is regulated by the small G proteins rac-1 and rhoA. Exp Dermatol. 2004; 13:70-77. [PubMed: 15009099]

36. Langevin HM, Bouffard NA, Badger GJ, Churchill DL, Howe AK. Subcutaneous tissue fibroblast cytoskeletal remodeling induced by acupuncture: Evidence for a mechanotransduction-based mechanism. J Cell Physiol. 2006; 207:767-774. [PubMed: 16511830]

37. Langevin HM, Bouffard NA, Churchill DL, Badger GJ. Connective tissue fibroblast response to acupuncture: Dose-dependent effect of bidirectional needle rotation. J Altern Complement Med. 2007; 13:355-360. [PubMed: 17480137]

38. Langevin HM, Bouffard NA, Fox JR, Palmer BM, Wu J, Iatridis JC, Barnes WD, Badger GJ, Howe AK. Fibroblast cytoskeletal remodeling contributes to connective tissue tension. J Cell Physiol. 2010; 226:1166-1175. [PubMed: 20945345]

39. Langevin HM, Churchill DL, Cipolla MJ. Mechanical signaling through connective tissue: A mechanism for the therapeutic effect of acupuncture. FASEB J. 2001; 15:2275-2282. [PubMed: 11641255]

40. Langevin HM, Churchill DL, Wu J, Badger GJ, Yandow JA, Fox JR, Krag MH. Evidence of connective tissue involvement in acupuncture. FASEB J. 2002; 16:872-874. [PubMed: 11967233]

41. Lee DJ, Rosenfeldt H, Grinnell F. Activation of ERK and p38 MAP kinases in human fibroblasts during collagen matrix contraction. Exp Cell Res. 2000; 257:190-197. [PubMed: 10854067]

42. Libert C. Inflammation: A nervous connection. Nature. 2003; 421:328-329. [PubMed: 12540886]

43. Lim JH, Gibbons HM, O'Carroll SJ, Narayan PJ, Faull RL, Dragunow M. Extracellular signalregulated kinase involvement in human astrocyte migration. Brain Res. 2007; 1164:1-13. [PubMed: 17644078]

44. Lin JG, Chen WL. Acupuncture analgesia: A review of its mechanisms of actions. Am J Chin Med. 2008; 36:635-645. [PubMed: 18711761]

45. Marinari B, Costanzo A, Viola A, Michel F, Mangino G, Acuto O, Levrero M, Piccolella E, Tuosto L. Vav cooperates with CD28 to induce NF-kappaB activation via a pathway involving Rac-1 and mitogen-activated kinase 1. Eur J Immunol. 2002; 32:447-456. [PubMed: 11813163]

46. Mavrommatis CI, Argyra E, Vadalouka A, Vasilakos DG. Acupuncture as an adjunctive therapy to pharmacological treatment in patients with chronic pain due to osteoarthritis of the knee: A 3armed, randomized, placebo-controlled trial. Pain. 2012; 153:1720-1726. [PubMed: 22727499]

47. Mi WL, Mao-Ying QL, Wang XW, Li X, Yang CJ, Jiang JW, Yu J, Wang J, Liu Q, Wang YQ, Wu GC. Involvement of spinal neurotrophin-3 in electroacupuncture analgesia and inhibition of spinal glial activation in rat model of monoarthritis. J Pain. 2011; 12:974-984. [PubMed: 21680256]

48. Montaner S, Perona R, Saniger L, Lacal JC. Multiple signalling pathways lead to the activation of the nuclear factor kappaB by the Rho family of GTPases. J Biol Chem. 1998; 273:12779-12785. [PubMed: 9582304]

49. Moulin DE, Clark AJ, Gilron I, Ware MA, Watson CP, Sessle BJ, Coderre T, Morley-Forster PK, Stinson J, Boulanger A, Peng P, Finley GA, Taenzer P, Squire P, Dion D, Cholkan A, Gilani A, Gordon A, Henry J, Jovey R, Lynch M, Mailis-Gagnon A, Panju A, Rollman GB, Velly A. Pharmacological management of chronic neuropathic pain - Consensus statement and guidelines from the Canadian Pain Society. Pain Res Manag. 2007; 12:13-21. [PubMed: 17372630]

50. Neary JT, Kang Y, Willoughby KA, Ellis EF. Activation of extracellular signal-regulated kinase by stretch-induced injury in astrocytes involves extracellular ATP and P2 purinergic receptors. J Neurosci. 2003; 23:2348-2356. [PubMed: 12657694]

51. Paramore LC. Use of alternative therapies: Estimates from the 1994 Robert Wood Johnson Foundation National Access to Care Survey. J Pain Symptom Manage. 1997; 13:83-89. [PubMed: 9095565]

52. Randolph BC, Peters MA. Analgesic effectiveness of ketorolac compared to meperidine in the rat formalin test. Anesth Prog. 1997; 44:11-16. [PubMed: 9481975]

53. Schnabel A, Poepping DM, Kranke P, Zahn PK, Pogatzki-Zahn EM. Efficacy and adverse effects of ketamine as an additive for paediatric caudal anaesthesia: A quantitative systematic review of randomized controlled trials. Br J Anaesth. 2011; 107:601-611. [PubMed: 21846679] 
54. Sun S, Cao H, Han M, Li TT, Zhao ZQ, Zhang YQ. Evidence for suppression of electroacupuncture on spinal glial activation and behavioral hypersensitivity in a rat model of monoarthritis. Brain Res Bull. 2008; 75:83-93. [PubMed: 18158100]

55. Tang JS, Qu CL, Huo FQ. The thalamic nucleus submedius and ventrolateral orbital cortex are involved in nociceptive modulation: A novel pain modulation pathway. Prog Neurobiol. 2009; 89:383-389. [PubMed: 19819292]

56. Thong T, Colbert AP, Larsen AP. An 8-channel skin impedance measurement system for acupuncture research. Conf Proc IEEE Eng Med Biol Soc. 2009; 2009:861-864. [PubMed: 19965129]

57. Vercelino R, Cunha TM, Ferreira ES, Cunha FQ, Ferreira SH, de Oliveira MG. Skin vasodilation and analgesic effect of a topical nitric oxide-releasing hydrogel. J Mater Sci Mater Med. 2013; 24:2157-2169. [PubMed: 23756965]

58. Vickers AJ, Cronin AM, Maschino AC, Lewith G, MacPherson H, Foster NE, Sherman KJ, Witt CM, Linde K. Acupuncture for chronic pain: Individual patient data meta-analysis. Arch Intern Med. 2012; 172:1444-1453. [PubMed: 22965186]

59. Wang P, Yang L, You X, Singh GK, Zhang L, Yan Y, Sung KL. Mechanical stretch regulates the expression of matrix metalloproteinase in rheumatoid arthritis fibroblast-like synoviocytes. Connect Tissue Res. 2009; 50:98-109. [PubMed: 19296301]

60. WHO Regional Office for the Western Pacific. WHO Standard Acupuncture Point Locations in the Western Pacific Region. Manila: World Health Organization, Western Pacific Region; 2008.

61. Woolf CJ. Central sensitization: implications for the diagnosis and treatment of pain. Pain. 2011; 152:2-15. [PubMed: 20692098]

62. Woolf CJ, Bennett GJ, Doherty M, Dubner R, Kidd B, Koltzenburg M, Lipton R, Loeser JD, Payne R, Torebjork E. Towards a mechanism-based classification of pain? Pain. 1998; 77:227-229. [PubMed: 9808347]

63. Woollam CH, Jackson AO. Acupuncture in the management of chronic pain. Anaesthesia. 1998; 53:593-595. [PubMed: 9709149]

64. Xiong J, Liu F, Zhang MM, Wang W, Huang GY. De-qi, not psychological factors, determines the therapeutic efficacy of acupuncture treatment for primary dysmenorrhea. Chin J Integr Med. 2011; 18:7-15. [PubMed: 21994026]

65. Yang CP, Chang MH, Liu PE, Li TC, Hsieh CL, Hwang KL, Chang HH. Acupuncture versus topiramate in chronic migraine prophylaxis: A randomized clinical trial. Cephalalgia. 2011; 31:1510-1521. [PubMed: 22019576]

66. Zhao ZQ. Neural mechanism underlying acupuncture analgesia. Prog Neurobiol. 2008; 85:355375. [PubMed: 18582529]

67. Zhou S, Schmelz A, Seufferlein T, Li Y, Zhao J, Bachem MG. Molecular mechanisms of low intensity pulsed ultrasound in human skin fibroblasts. J Biol Chem. 2004; 279:54463-54469. [PubMed: 15485877]

68. Zijlstra FJ, van den Berg-de Lange I, Huygen FJ, Klein J. Anti-inflammatory actions of acupuncture. Mediators Inflamm. 2003; 12:59-69. [PubMed: 12775355] 
A
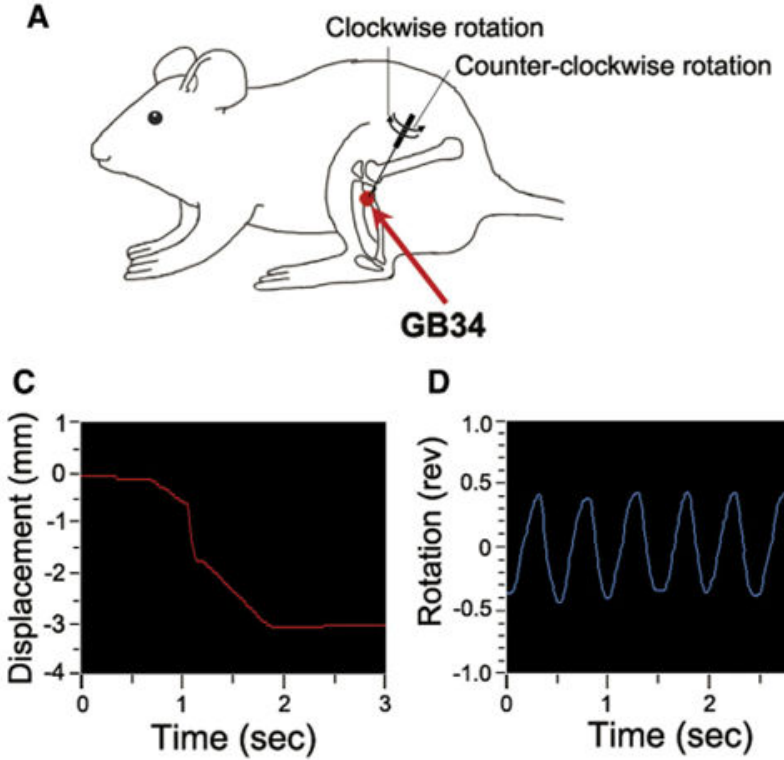

D

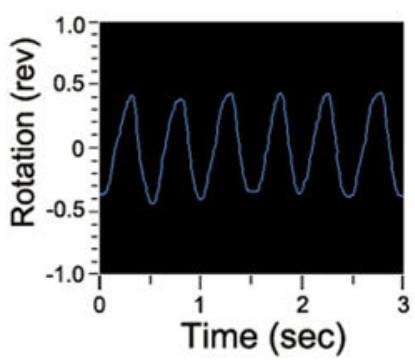

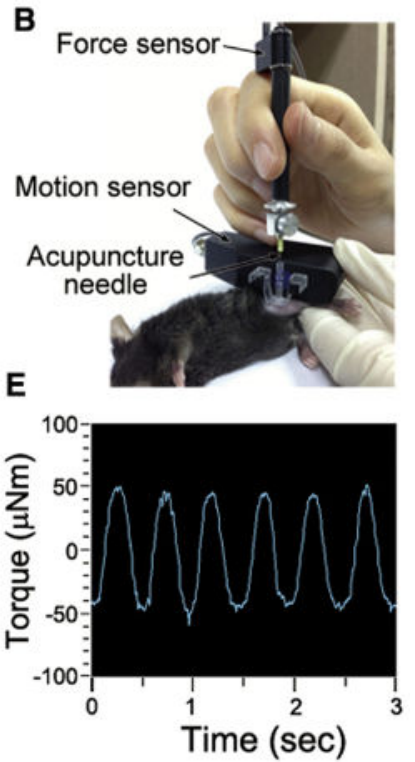

Figure 1.

Details of acupuncture needling. (A) Location of the acupuncture point GB34 used in this study. GB34 (Yangneungcheon), at the intersection of the lines from the anterior borders to the head of the fibula. (B-E) The depth and the rotation rate of the acupuncture needling were quantified by Acusensor. (B) Acusensor technology and measuring method. (C-E) The linear translation of the needle (displacement) and the turning of the needle (rotation) was measured using a motion sensor. The rotational force acting on the needle (torque) was measured using a force sensor. Acupuncture needles were inserted at GB34 to a depth of 3 $\mathrm{mm}(\mathbf{C})$ and rotated at a rate of 2 spins per second (1 spin consisted of clockwise rotation of $180^{\circ}$ and counterclockwise rotation of $180^{\circ}$ ) for 10 seconds (D, E). Abbreviation: Rev, revolution. 


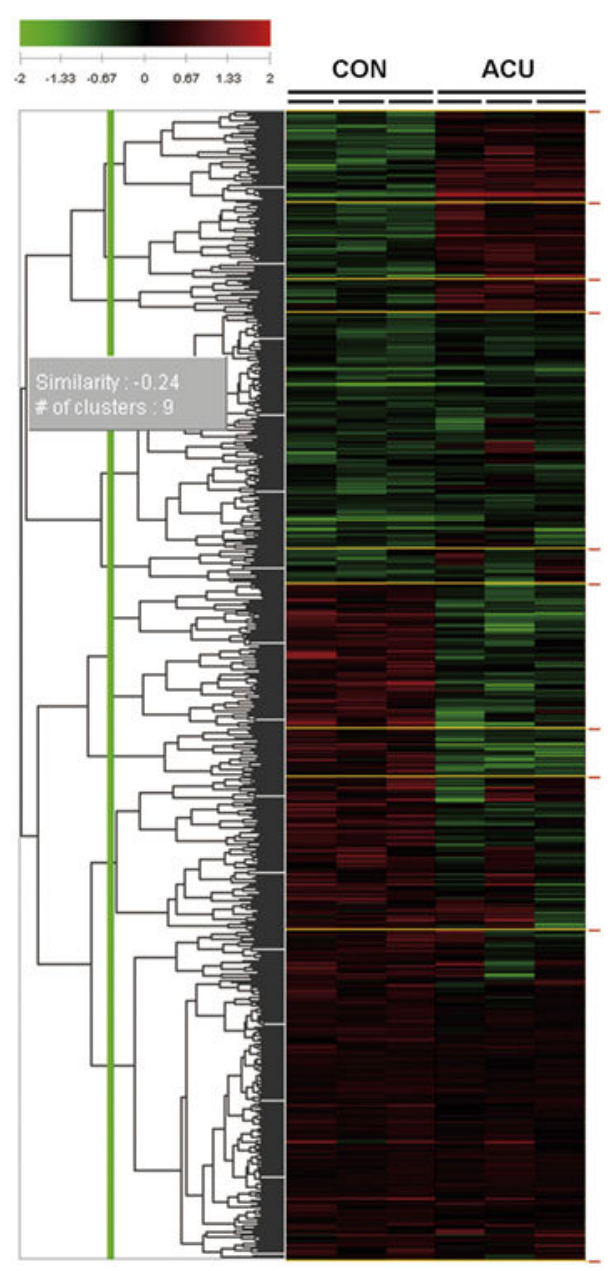

Figure 2.

Microarray analysis of gene expression profiles in the ACU and CON groups. A total of 236 genes changed after acupuncture needling $(1.5$-fold change, $P<.05$, Student t-test compared to the CON group) in the 3 controls and the 3 acupuncture-stimulated skin samples. Of these genes, 110 were up-regulated and 126 were down-regulated. Green: down-regulation; Red: up-regulation. $\mathrm{n}=3$ each for CON and ACU. 

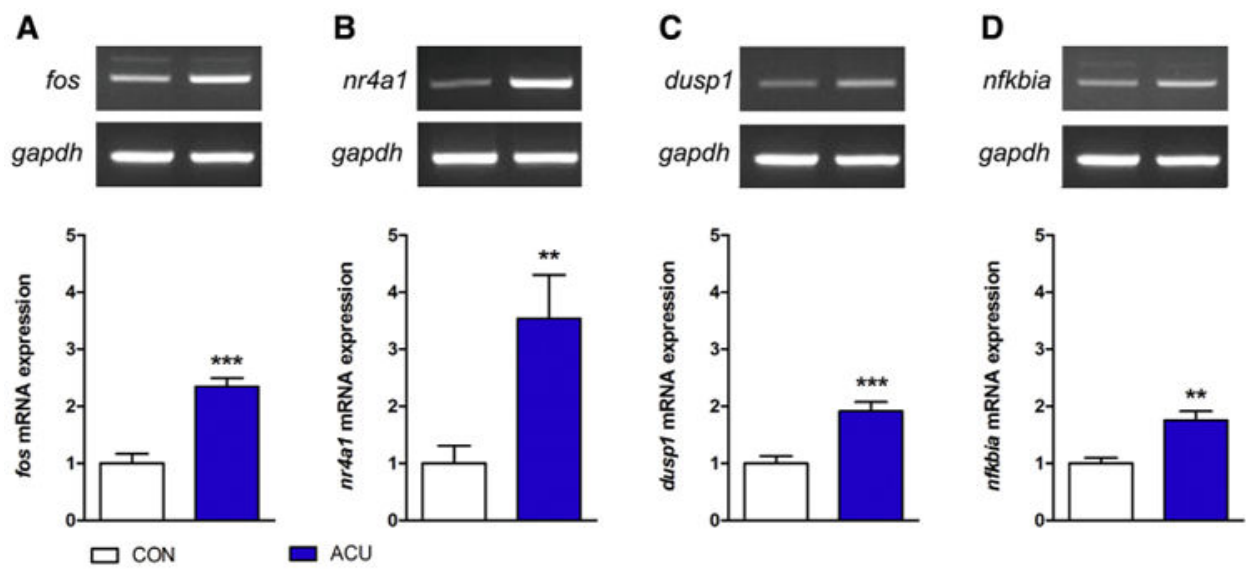

Figure 3.

Expression levels of fos, $n r 4 a l$, duspl, and $n f k b i a$ mRNA after acupuncture needling. (A-D) Sixty minutes after acupuncture needling, the mRNA levels of fos, nr $4 a 1$, duspl, and nfkbia were determined by RT-PCR, and gapdh served as a control for the RT-PCR. $(* * P<.01$, $* * * P<.001$, Student $\mathrm{t}$-test compared to the CON group; each $\mathrm{n}=6$ ). Error bars indicate the SEM. 
A
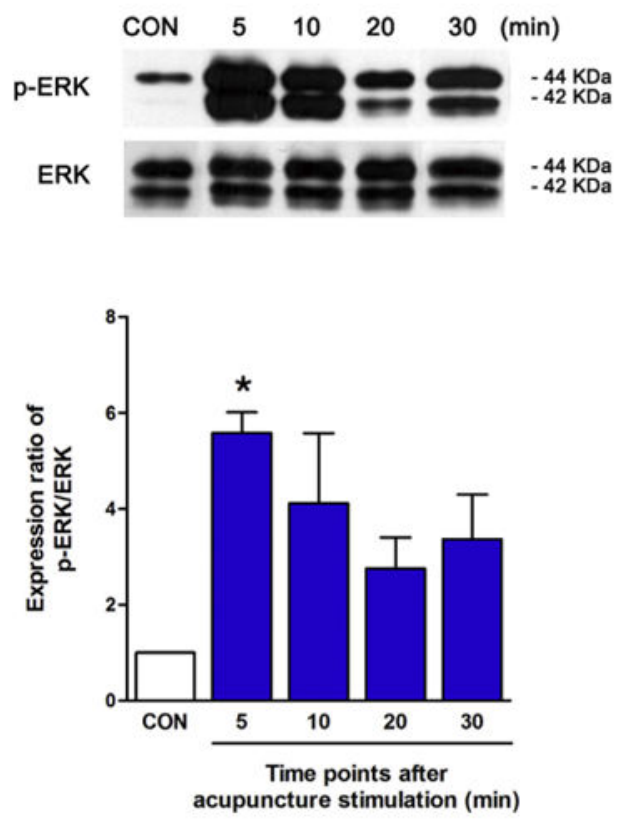
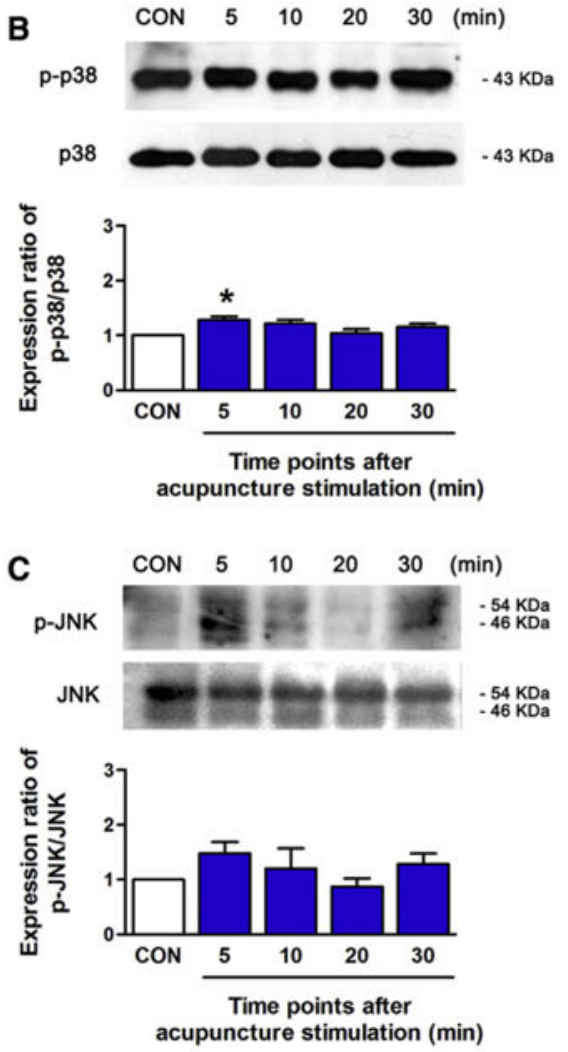

Figure 4.

Changes in the levels of phospho-ERK, phospho-p38, and phospho-JNK in the skin layers after acupuncture needling. (A-C) Phospho-ERK, phospho-p38, and phospho-JNK levels in the skin layers were determined at 5,10,20, and 30 minutes after acupuncture needling by Western blot analysis. After acupuncture needling, the activation of phospho-ERK was increased more than double, compared to the CON group (A). The changes in phospho-p38 and phospho-JNK were small and not significant compared to ERK activation $(\mathbf{B}, \mathbf{C})$. ( ${ }^{*} P<$. 05, 1-way ANOVA followed by the Newman-Keuls test compared to the CON group; each $\mathrm{n}=3$ ). Error bars indicate the SEM. 


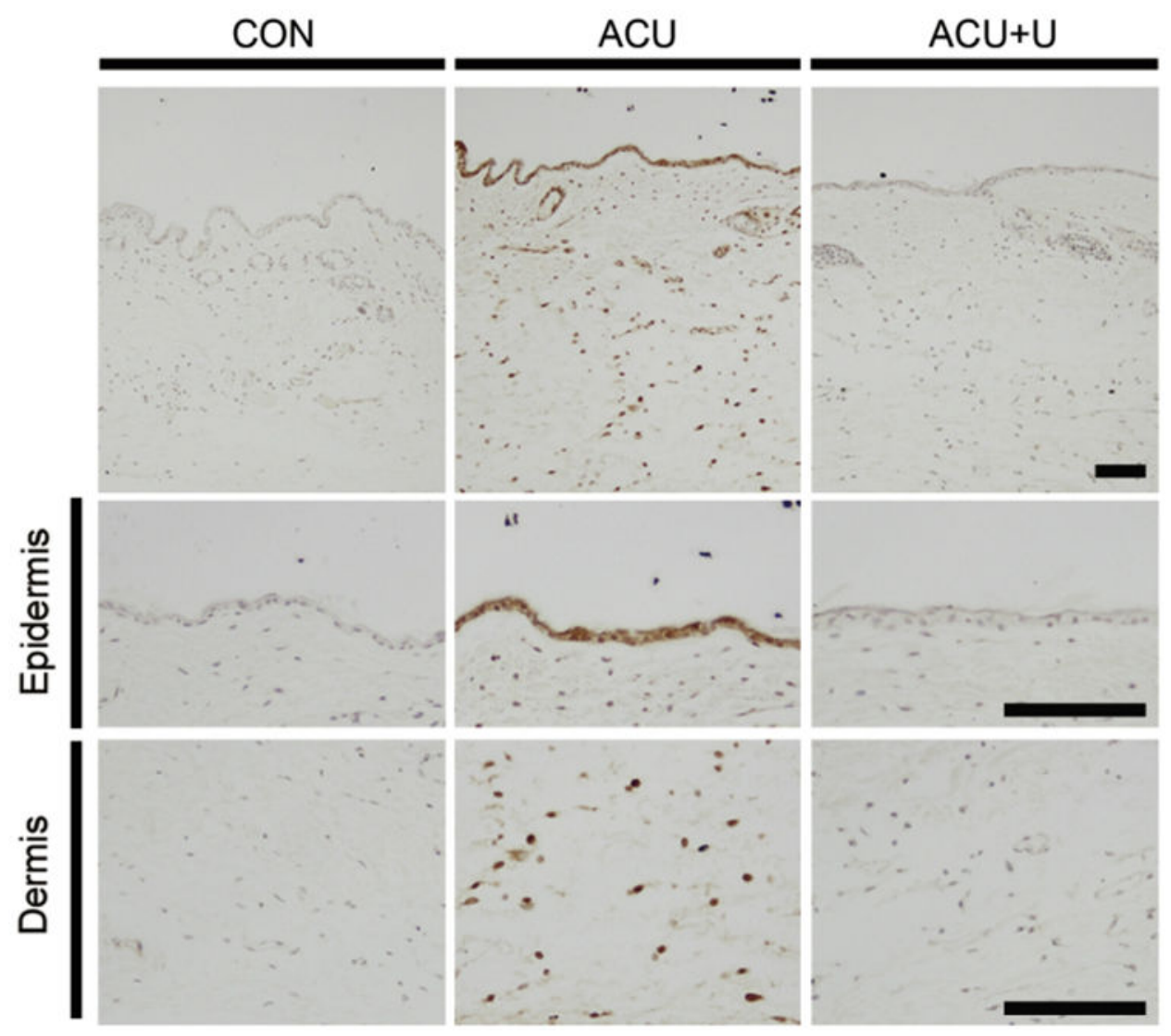

Figure 5.

Changes in the phospho-ERK level in the skin layers after acupuncture. Five minutes after acupuncture needling, phospho-ERK levels in the skin layers were determined through immunohistochemistry. Phospho-ERK activation was detected in the epidermis and the dermis around the acupuncture point. These signals were attenuated by U0126. U0126 was administered 15 minutes before acupuncture needling. Scale bar: $100 \mu \mathrm{m}$. 


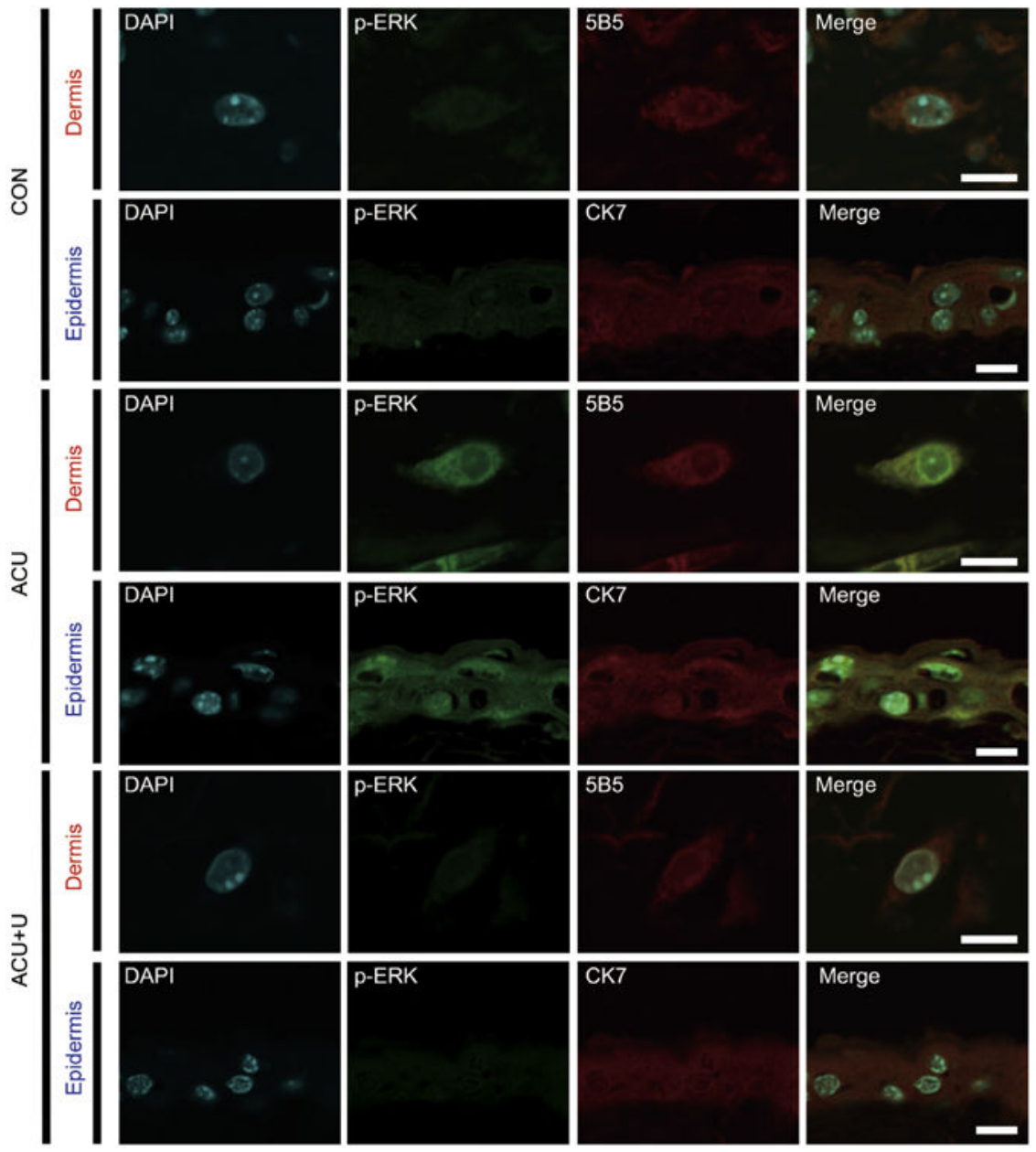

Figure 6.

Changes in the level of phospho-ERK expression in the epidermis and dermis after acupuncture. Five minutes after acupuncture needling, phospho-ERK levels in the epidermis and the dermis layers were determined by immunofluorescence. The activation of ERK was detected in the keratinocytes of the epidermis (colocalized with the keratinocyte marker CK7) and in the fibroblast of the dermis (colocalized with the fibroblast marker 5B5). These signals were attenuated by U0126 administration 15 minutes before acupuncture needling. Blue: counterstain with DAPI; Green: phospho-ERK expression; Red: CK7 or 5B5 expression. Abbreviation: DAPI, 4',6-diamidino-2-phenylindole. Scale bar: $10 \mu \mathrm{m}$. 

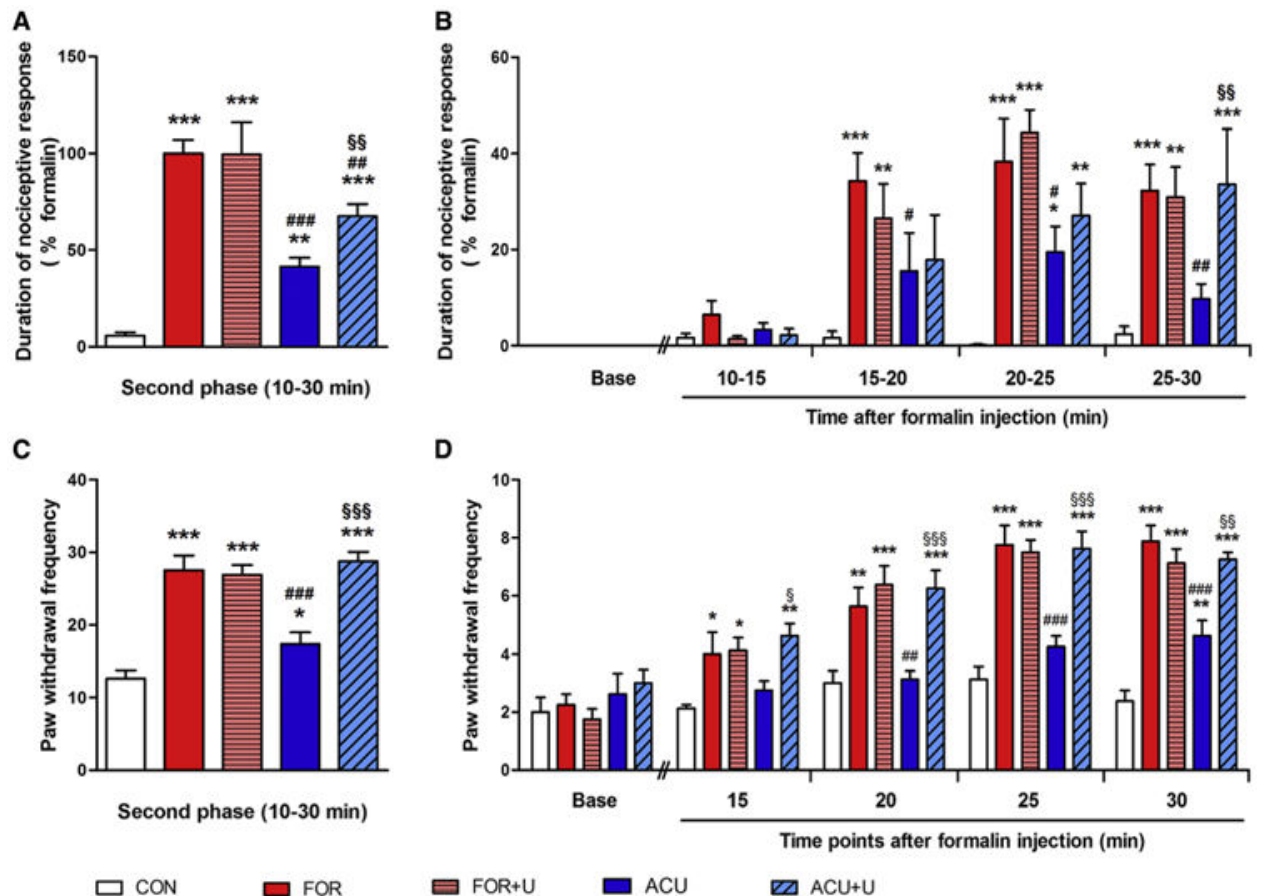

D

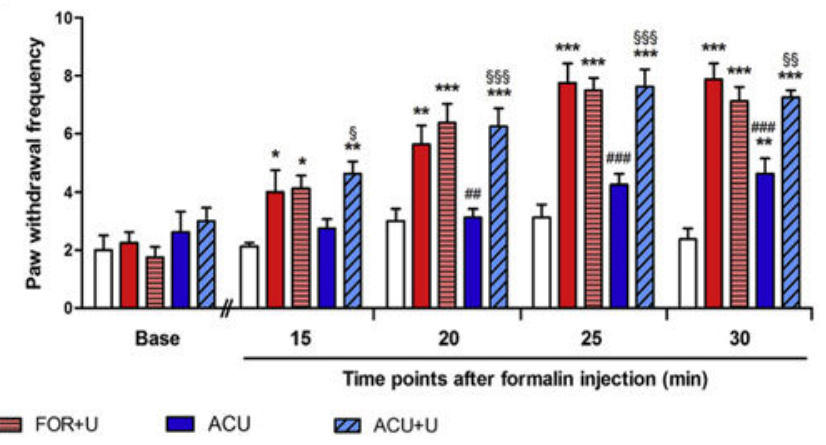

Figure 7.

U0126 administration reversed the analgesic effect of acupuncture needling in the formalininduced pain model. (A, B) Formalin-induced nociceptive behavior during the second phase. Ten minutes after the formalin injection, nociceptive behavior, such as flinching, licking, and biting the right hind paw, was recorded for 20 minutes, and the total time was analyzed (A). Nociceptive behavior for 5-minute blocks during the second phase (B). (C, D) Formalin-induced mechanical allodynia during the second phase. After formalin injection and acupuncture needling, Von Frey filaments exerting $.6 \mathrm{~g}$ of force were applied a total of 10 times to the plantar surface of the right hind paw every 5 minutes. The frequency of positive responses was calculated and the total frequency was summated $(\mathbf{C})$. The mechanical threshold for 5-minute blocks during the second phase (D). $\left({ }^{*} P<.05,{ }^{*} P<.01\right.$,

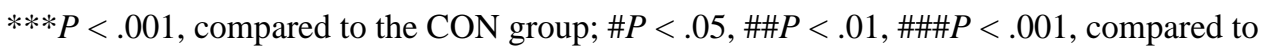
the FOR group; $\S P<.05, \S \S P<.01, \S \S \S P<.001$, compared to the ACU group. One-way ANOVA was followed by the Newman-Keuls test [A,C] and 2-way ANOVA was followed by the Bonferroni test $[\mathbf{B}, \mathbf{D}]$, each $\mathrm{n}=8$ ). Error bars indicate SEM. 

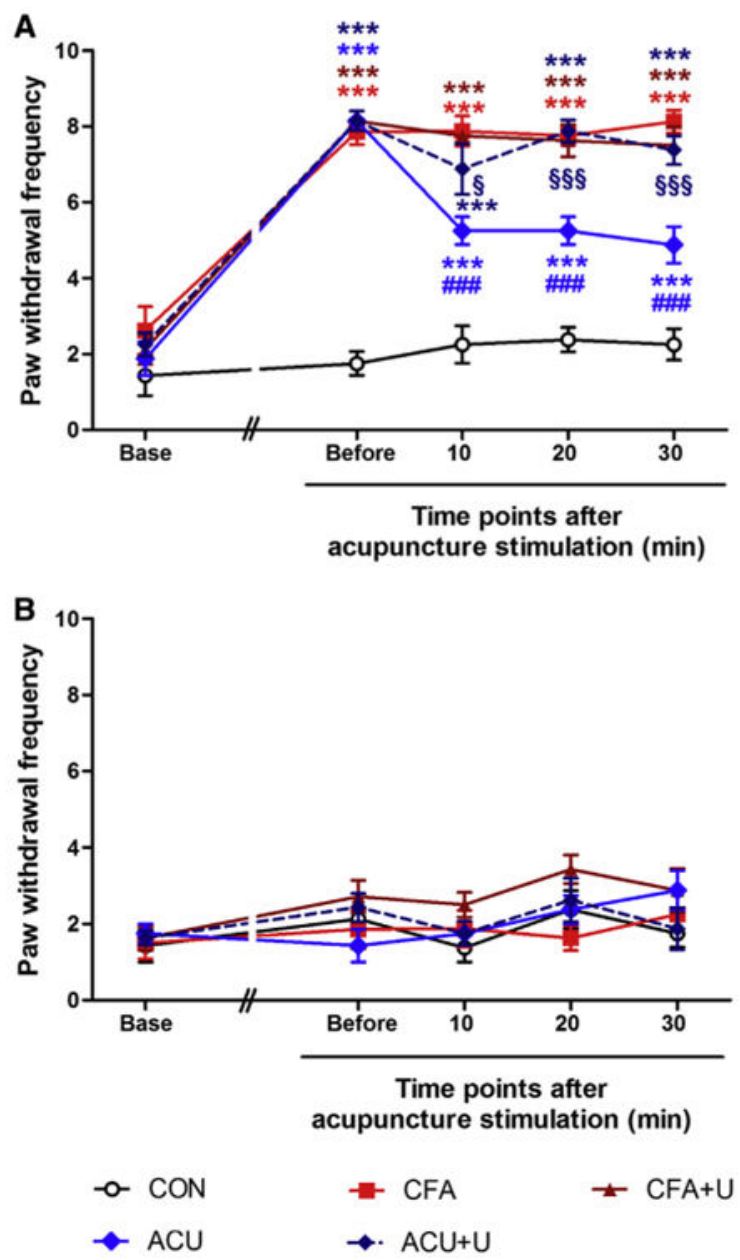

Figure 8.

U0126 administration reversed the analgesic effect of acupuncture needling on the CFAinduced mechanical threshold. The GB34 acupuncture point was stimulated by acupuncture 15 minutes after U0126 administration. Von Frey filaments exerting $.6 \mathrm{~g}$ of force were applied a total of 10 times to the plantar surface of the right (ipsilateral, A) and left (contralateral, B) hind paw every 10 minutes. The frequency of positive responses was calculated. Before the CFA injection, the mechanical threshold of the baseline was assessed (Base). Four days after CFA injection, the mechanical threshold was assessed before acupuncture needling (Before). Von Frey filaments were applied 10, 20, and 30 minutes after acupuncture needling $(* * * P<.001$, compared to the CON group; \#\#\#P<.001, compared to the CFA group; $\S P<.05, \S \S \S P<.001$, compared to the ACU group. Two-way ANOVA was followed by the Bonferroni test, each $n=8$ ). Error bars indicate SEM. 


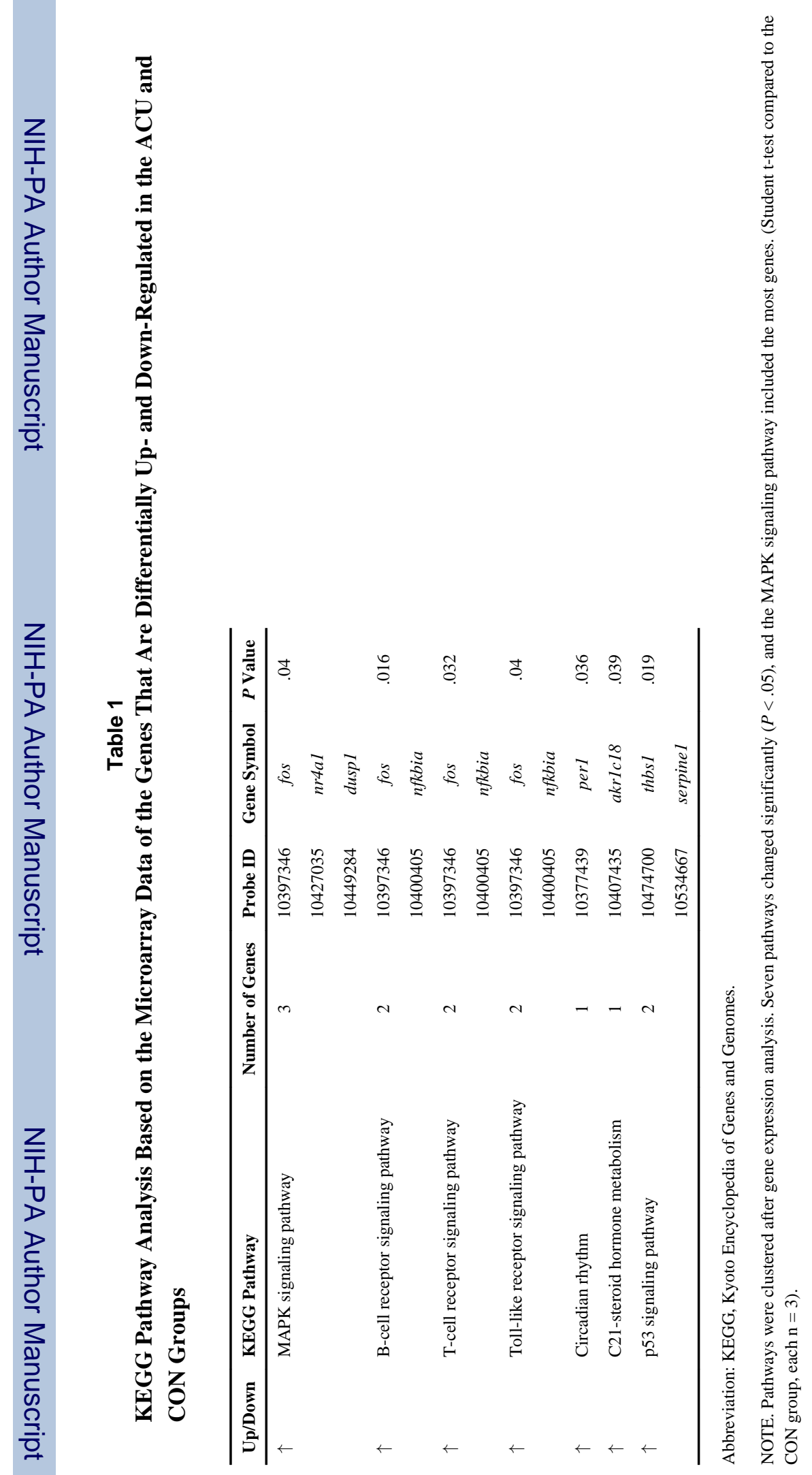

J Pain. Author manuscript; available in PMC 2014 October 14. 